\title{
PERENCANAAN PERATURAN ZONASI DI KAWASAN KONSERVASI (STUDI KASUS PECINAN SEMARANG)
}

\author{
Jamilla Kautsary \\ Program Studi Perencanaan Wilayah dan Kota Universitas Islam Sultan Agung Semarang \\ Penulis Korespondensi e-mail : jamilla@unissula.ac.id
}

\begin{abstract}
Zoning regulations for spatial planning in Indonesia are an integral part of the Spatial Detail Plan. The zoning regulation serves as a technical reference for the utilization and control of spatial utilization. This is done to maintain the use of space that develops in accordance with the characteristics of the zone and to minimize negative impacts. Traditional Chinatown settlements have certain characteristics that develop according to historical and spiritual factors of the community. Behind this characteristic is a meaning that is considered very important for this community, so that it cannot be arbitrarily arranged. This paper examines zoning regulations implemented in the Semarang Chinatown area and how far the local characteristics of the zone are used as a consideration of planning zoning regulations for spatial use in the region. This paper uses a rationalistic qualitative deductive approach with empirical description techniques. Some important findings identified from this paper are: first zoning regulations applied in the Spatial Detail Plan are still minimal and limited to the determination of spatial functions, the network system that serves related to the basic coefficient of build, height of the building. Both unique characteristics that must be considered in zoning arrangements in Chinatown such as activity grouping, spatial use rules, especially in skewers zones, and rules of space use around places of worship or sanctified spaces, building height and coefficient of existing buildings have not been considered at all. Recommendations that can be given from this paper are that the minimum zoning regulation components that apply in Indonesia according to the applicable standards are applied with special consideration of the unique characteristics of the region in the spatial arrangement.
\end{abstract}

Keywords: Zoning, Conservation, Traditional, Chinatown

\begin{abstract}
ABSTRAK
Peraturan zonasi dalam penataan ruang di Indonesia merupakan bagian yang tidak terpisahkan dari Rencana Detail Tata Ruang. Peraturan zonasi tersebut berfungsi sebagai rujukan teknis untuk pemanfaatan dan mengendalikan pemanfaatan ruang. Hal ini dilakukan untuk mejaga agar pemanfaatan ruang yang berkembang tetap sesuai dengan karakteristik zona serta untuk meminimalkan dampak negatif. Permukiman tradisional Pecinan memiliki karakteristik tertentu yang berkembang sesuai faktor kesejarahan dan spiritual dari masyarakatnya. Dibalik karakteristik yang ada ini terselip makna yang dianggap sangat penting bagi komunitas ini, sehingga tidak bisa sembarangan untuk diatur. Tulisan ini mengkaji peraturan zonasi yang dilakukan di kawasan Pecinan Semarang dan seberapa jauh karakteristik lokal zona digunakan sebagai pertimbangan perencanaan peraturan zonasi pemanfaatan ruang di kawasan tersebut. Tulisan ini menggunakan pendekatan deduktif kualitatif rasionalistik dengan teknik deskripsi empiris. Beberapa temuan penting yang terindentifikasi dari tulisan ini adalah: pertama peraturan zonasi yang diterapkan dalam Rencana Detail Tata Ruang masih minim dan terbatas pada penentuan fungsi ruang, sisten jaringan yang melayani terkait koefisien dasar bangun, ketinggian bangunan. Kedua karakteritik unik yang harus dipertimbangkan dalam pengaturan zonasi di Pecinan seperti pengelompokan kegiatan, aturan pemanfaatan ruang khususnya di zona tusuk sate, dan aturan pemanfaatan ruang disekitar tempat peribadatan atau ruangruang yang disucikan, keinggian bangunan dan koefisien bangunan eksisting belum di pertimbangkan sama sekali. Rekomendasi yang bisa diberikan dari tulisan ini adalah minimal komponen peraturan zonasi yang berlaku di Indonesia sesuai standarat yang berlaku diterapkan dengan pertimbangan khusus karakteristik unik kawasan dalam pengaturan ruang.

Kata kunci: Zonasi, Konservasi, Tradisional, Pecinan
\end{abstract}


Jurnal Planologi Vol. 15, No. 2, Oktober 2018

Available : http://jurnal.unissula.ac.id/index.php/psa

\section{PENDAHULUAN}

\subsection{Latar Belakang}

Peraturan zonasi dalam ketentuan perundangan penataan ruang di Indonesia merupakan bagian yang tidak terpisahkan dari Rencana Detail Tata Ruang. Peraturan zonasi tersebut berfungsi sebagai rujukan teknis untuk pemanfaatan (investasi) dan mengendalikan pemanfaatan ruang (Peraturan Pemerintah No. 15 Tahun 2010 tentang Penyelenggaraan Penataan Ruang). Peran penting aturan zonasi adalah untuk mejaga agar pemanfaatan ruang yang berkembang tetap sesuai dengan karakteristik zona (sesuai dengan rencana) serta untuk meminimalkan dampak negatif (Peraturan Mentri PU No. 20 Tahun 2012 Tentang Pedoman Penyusunan Rencana Detail Tata Ruang Kota)

Peraturan zonasi sesuai dengan peraturan tersebut, memuat apa yang boleh, boleh bersyarat, boleh terbatas dan yang tidak boleh di lakukan pada zona tertentu. Ketentuantetentuan zonsi tersebut tentu akan berbeda aturanya di setiap zona pemanfaatan, tergantung pada karakteristik zona. Demikian juga halnya dengan zona-zona pada kawasan yang sudah ditetapkan sebagai bagian kawasan konservasi di Kota Semarang.

Pada kasus pengaturan zona di kawasan Semarang Tengah khususnya pada kawasan Pecinan karakteristik unik zona sebagai bagian permukiman tradisional etnis Tionghoa belum dipertimbangkan. Kawasan ini sesuai dengan Perda No. 14 tahun 2011 tentang RTRW Kota Semarang 2011-2031 diarahkan sebagai kawasan Perkantoran dan Perdagangan dan Jasa (Pasal 10 ayat (2)) serta merupakan bagian dari kawasan Cagar Budaya (Pasal 69). Sementara pada Perda No. 6 Tahun 2004 tentang Rencana Detail Tata Ruang Kota Semarang (Bagian Wilayah Kota I) peruntukan ini di rincikan menjadi fungsifungsi: permukiman, perdagangan dan jasa, campuran perdagangan dan jasa, permukiman, perkantoran, spesifik/budaya.

Belum adanya pertimbangan karakreistik unik zona ini pada perkembangan pemanfaatan utamanya dalam upaya konservasi kawasan kemudian memunculkan adanya konflik aktivitas yang berdimensi ruang dan waktu (Jamilla Kautsary, 2006). Hal ini dikarenakan karakteristik unik kawasan kurang dikenali. Guna menghindari adanya konflik dan dampak negatif terkait dengan upaya konservasi kawasan cagar budaya dan mengarahkan agar zona perkembangan sesuai dengan karakteristik lokal zona maka perlu kiranya untuk mengkaji mengkaji peraturan zonasi yang ditetapkan di kawasan tersebut serta melihan seberapa jauh karakteristik lokal zona di pertimbangan perencanaan 
peraturan zonasi pemanfaatan ruang di kawasan tersebut dalam penyusunan rencana detail tata ruang (RDTRK ). Manfaat yang diharapkan dari tulisan ini adalah:

a) Memelihara karakteristik unik zona yang telah terbentuk dari tinteraksi positif antara ruang dan masyarakat tetap bisa terjaga dengan baik.

b) Mencegah munculnya dampak negatif dari kegiatan baru yang tidak sesuai dengan karakteristik zona.

\subsection{Kajian Teori}

\subsubsection{Peraturan Zonasi}

Zoning secara umum diartikan sebagai bentuk pembagian lingkungan kota ke dalam zona-zona dan menetapkan pengendalian pemanfaatan ruang/ memberlakukan ketentuan hukum yang berbeda-beda (Zulkaidi, dan Petrus Natalivan., 2008). Zonasi dikawasan Konservasi merupakan pembagian lokasi yang mengacu pada apa yang dapat dan tidak dapat dilakukan di area/zona yang pemanfaatan berbeda dari kawasan konservasi dalam hal pemanfaatan, pengembangan, pemeliharaan dan pengelolaan sumber daya alam dan buatan. Zonasi membantu mengurangi atau menghilangkan konflik antara pengguna yang berbeda dari Kawasan Konservasi, untuk meningkatkan kualitas kegiatan seperti pariwisata dan untuk memfasilitasi kepatuhan. Zonasi adalah metode yang diterima secara luas untuk menjauhkan orang dari area yang paling sensitif dan untuk membatasi dampaknya penggunaan kawasan konservasi (Rotich, Dorothy., 2012). Sementara peraturan zonasi merupakan ketentuan yang mengatur tentang klasifikasi zona, pengaturan lebih lanjut mengenai pemanfaatan lahan, dan prosedur pelaksanaan pembangunan (Cook Jr, Robert S., 1980). Rincian materi zoning meliputi di Indonesia yang digunakan oleh Kementrian Pekerjaan umum (Zulkaidi, dan Petrus Natalivan., 2008):

a) Kegiatan yang diperbolehkan

b) Kegiatan yang dilarang

c) Aturan khusus untuk kegiatan

d) Kegiatan tambahan dan aturannya

e) Kegiatan bersyarat dan aturannya

f) Pengecualian khusus

g) Ketentuan luas persil (minimum/maksimum)

h) Ketentuan luas pekarangan (sempadan depan, samping, belakang)

i) KDB maksimum

j) Luas minimum lantai bangunan 
k) Batas tinggi bangunan

1) Variansi

\subsubsection{Konservasi}

Konservasi: menurut Otto, Wayne O (1998) merupakan seluruh upaya yang menjadi payung dari semua kegiatan pelestarian sejarah yang secara spesifik dapat menyakut bangunan ataupun lokasi yang mengandung nilai sejarah. Tindakan konservasi ini bisa berupa restorasi, rehabilitasi dan renovasi, revitalisasi, replikasi, relokasi dsb. Tujuan utama dari kegiatan konservasi adalah:

a. Melestarikan bangunan/arsitektur kota yang ada sekarang dan mengarahkan perkembangannya dimasa datang serta bukan mengembalikan kesan masa lalu (living haritage)

b. Menjaga agar tempat yang menarik dan dapat berubah bisa dimanfaatkan dengan cara yang sesuai tanpa menghancurkan.

c. Menjaga stabilitas dan gaya hidup penduduk yang serasi dengan lingkungan terbangun (bukan mengekploitasi)

\subsubsection{Pecinan Semarang}

Pecinan merupakan perkampungan yang dibangun dan dihuni oleh masyarakat etnis Tionghoa berdasarkan aspek spiritual dan kesejarahan komunitas, sehingga membentuk struktur internal permukiman yang berlapis (Jamilla Kautsary, 2015). Kawasan Pecinan dikenal sebagai kantong kosmopolitan yang memerankan peran yang sangat penting dalam dunia perdagangan dan sebagai pusat pertumbuhan (Riyanto, 2004). Pada jaman Belanda kantong ini dimanfaatkan sebagai salah satu komponen jalur distribusi hasil bumi (Widodo, 1988). Pada masa ini, Belanda menerapkan zona permukiman berdasarkan etnis atau yang dikenal dengan Wijkenstelse. Aturan ini sangat berperan menciptakan batas yang tegas dengan kelompok pemukim berdasarkan etnis dan memunculkan nama-nama kampung seperti kampung Pecinan, Pekojan (etnis Arab, Pakistan, Gujarat), Melayu dan sebagainya (Liem, TJ., 1931)

Fungsi utama kawasan Pecinan saat ini secara umum terlihat sebagai kawasan perdagangan dan jasa, tetapi jika dicermati lebih dalam karakter perdagangan dan jasa di kawasan ini berbeda dengan kawasan perdagangan dan jasa lainnya di kota Semarang. Perdagangan di kawasan ini cenderung mengelompok sesuai dengan barang dagangannya sehingga melahirkan centra-centra perdagangan seperti perdagangan kain di Gang Warung, Emas di Gang Pinggir, Hasil bumi di Gang Baru, kegiatan perbangkan di Gang 
Tengah. Sementara dari penampakan fisik juga dapat diamati adanya bangunan pemujaan berupa Kelenteng di tiap ujung gang (jalan tusuk sate atau di sepanjang sungai Kalisemarang mengarah kedalam kawasan. Ruang tusk sati bagi masyarakat Tionghoa dianggap Tabu untuk didirikan bangunan selain bangunan pemujaan. Pada jalan-jalan utama banyak terlihat adanya bangunan berupa ruko yang memanjang ke balangan dan pada bangunan kelenteng besar dapat dijumpai tipe bangunan lainnya berupa bangunan courdyard. Bangunan-bangunan yang ada di pecnan ini rata-rata memiliki koefisien lantai bangunan hampir 100\% dengan ketinggian berfareasi antara 204 lantai (Jamilla Kautsary, 2015).

Selain karakteristik unik di atas, Kawasan permukiman Pecinan ini dibangun melalui sejarah panjang proses bermukim etnis Tionghoa di Semarang dan kepercayaan spirituan yang kuat dari ajaran Tri Dharma. Hal ini menjadikan ruang-ruang dikawasan ini memiliki makna spesifik bagi masyarakatnya. Makna ruang yang dikenali di kawasan ini dan turut mewarnai pada sistem pengaturan organisasi ruang di kawasan ini antara lain adalah R. Perlindungan, R. Penghidupan, R. Jut bio, R. Hoki, R. Barbagi (Kung Tek), R. Bersyukur (Gan Ji), R. Laku Bakti (Hsiao/Houw), R. Satya/Zhong, R. Ekspresi dan R Teladan. Makna-makna ini kemudian mempengaruhi meunculnya konsep-konsep ruang yang berua ruang kebertahanan, ruang penghormatan, ruang laku bakti dan ruang harmoni. Pengaturan pada beberapa fungsi utama ruang dengan makna-makna dan konsep-konsep tersebut berkaitan dengan kepercayaan spiritual dan faktor kesejarahan yang sampai saat ini memiliki aturan ketat dalam pemenfaatan dan pembangunannya, sehingga zona ini tidak bisa diatur dengan peraturan yang biasa berlaku di kawasan perdagangan dan jasa atau permukiman secara umum. (Jamilla Kautsary, 2017). 


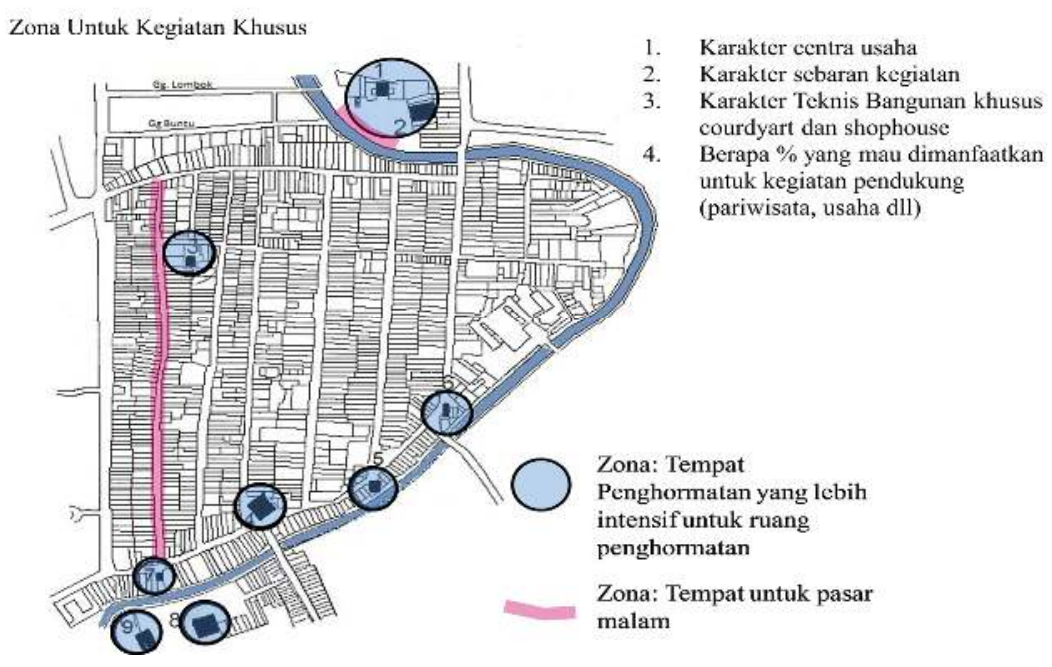

Gambar 1. Peta Rekomendasi Zona Kegiatan Revitalisasi Sumber: Jamilla Kautsary, 2015

\section{METODOLOGI}

Metodependekatan dalam tulisan ini menggunakan pendekatan deduktif rasionalistik. Metode deduksi ini lebih bersigat menguji teori umum ke kasus-kasus. Teori dalam metode deduktif ini menurut Alexander, Ernest, R. (1986), merupakan kerangka yang harus dipergunakan untuk membentuk struktur penelitian yang baik. Data dalam penelitian ini lebih banyak mengunakan data primer dan teknik analisis yang digunakan adalah diskritif empiri.

Lingkup pembahasan materi bahasan tulisan sesuai dengan tujuan ini adalah mengkaji peraturan zonasi yang dirlekukan di kawasan Pecinan semarang dan seberapa jauh karakteristik lokal zona digunakan sebagai pertimbangan perencanaan peraturan zonasi pemanfaatan ruang di kawasan tersebut. Ruang lingkup wilayah penelitian Kawasan Pecinan Semarang. Sesuai dengan tujuan maka parameter aturan zonasi yang akan dilihat adalah parameter yang saat ini berlaku di Indonesia berupa:
a) Kegiatan yang diperbolehkan
b) Kegiatan yang dilarang
c) Aturan khusus untuk kegiatan
d) Kegiatan tambahan dan aturannya
e) Kegiatan bersyarat dan aturannya
f) Pengecualian khusus
g) Ketentuan luas persil (minimum/maksimum)
h) Ketentuan luas pekarangan (sempadan depan, samping, belakang) 

i) $\mathrm{KDB}$ maksimum
j) Luas minimum lantai bangunan
k) Batas tinggi bangunan
1) Variansi

\section{HASIL DAN PEMBAHASAN}

\subsection{Penetapan Kawasan Cagar Budaya Kota Semarang}

Peraturan Daerah Kota Semarang No. 14 tahun 2011 merupakan bagian dari Bagian wilahay Kota I dengan fungsi utama sebagai pusat perdagangan dan jasa. Pada perda ini khusunya Pasal 69 (1) kawasan ini juga ditetapkan sebagai bagian kawasan cagar budaya. Kawasan cagarbudaya ini sebagaimana dimaksud dalam Pasal 66 huruf b di Kota Semarang meliputi : a. Kawasan Kota Lama; b. Kawasan Petudungan; c. Kawasan Kampung Kulitan; d. Kawasan Kampung Batik; e. Kawasan Pecinan; f. Kawasan Johar; g. Kawasan Kampung Melayu; h. Kawasan Kampung Kauman; i. Kawasan Tugu Muda; j. Kawasan Kampung Senjoyo; k. Kawasan Sam Po Kong; 1. Kawasan Perumahan PJKA di Kedungjati; m. Kawasan Makam Sunan Terboyo; dan n. Kawasan Kampung Sekayu.

Semantara dalam dokumen Pelaksanaan Program Penataan Dan Pelestarian Kota Pusaka (P3KP) Kota Pusaka Semarang, Tahun 2013, Direktorat Jenderal Penataan Ruang, Kementerian Pekerjaan Umum kawasan konservasi yang ditetapkan sebagai bagian kota Pusaka Kota Semarang seperti terlihat pada Peta Berikut

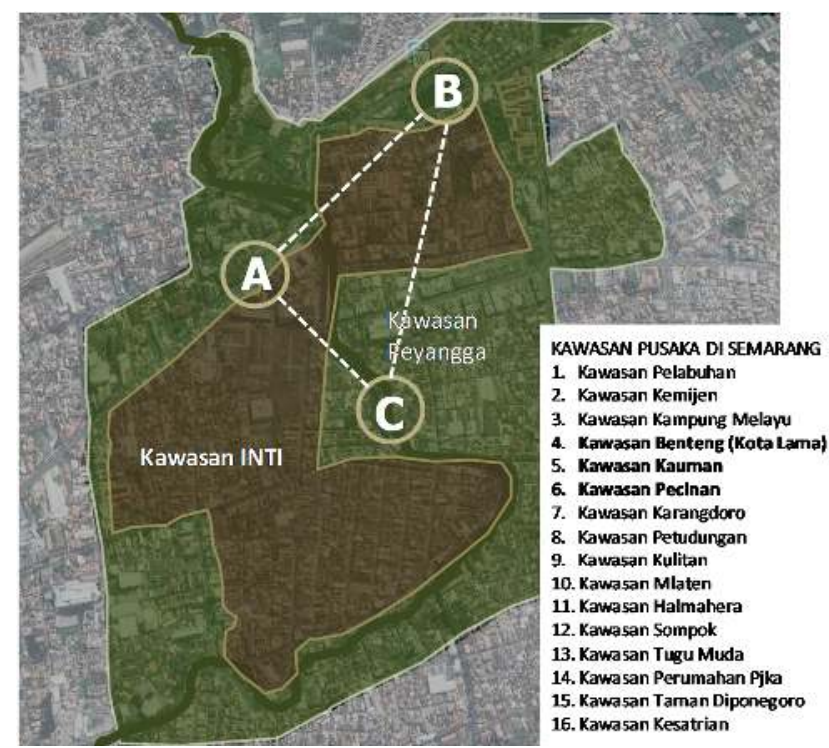

Gambar 1. Peta Kawasan Pusaka Di Kota Semarang

Sumber: Dokumen Pelaksanaan Program Penataan Dan Pelestarian Kota Pusaka (P3KP) Kota Pusaka Semarang, Tahun 2013 
Kawasan prioritas sesuai dokumen P3KP merupakan kawasan yang diprioritaskan penanganannya dalam pelestarian pusaka. Kawasan ini memiliki luas 141,5 Ha yang terdiri dari :

$$
\begin{array}{lll}
\text { 1. Kawasan Benteng } & \text { 21,2 Ha } \\
\text { 2. Kawasan Kauman } & : \text { 17,5 Ha } \\
\text { 3. Kawasan Pecinan } & : \text { 35,8 Ha } \\
\text { 4. Kawasan Petudungan } & : 3,6 \mathrm{Ha} \\
\text { 5. Kawasan Kulitan } & : \text { Pendukung } & : \text { Ha } \\
\text { 6. Kawasan Ha } &
\end{array}
$$

Penggunaan lahan di kawasan prioritas didominasi perumahan dan perdagangan jasa yang padat. Di kawasan ini dilalui oleh sungai yang pernah menjadi sarana transportasi penting di masanya yaitu Kali Semarang. Keterkaitan antara kawasan yang satu dengan yang lainnya menjadi tonggak sejarah peradaban Kota Semarang.

1. Kawasan Kota Lama atau : Aktivitas perkantoran swasta, Kota Benteng perumahan, jasa, pertahanan dan keamanan, gudang, perdagangan, keagamaan, PKL, pariwisata

2. Pendukung Kota Lama atau : Aktivitas perumahan, keagamaan, Kawasan Benteng perkantoran, transportasi, pariwisata

3. Kawasan Kauman : Aktifitas perdagangan jasa, keagamaan, perumahan, pariwisata

4. Kawasan Pecinan : Aktifitas perdagangan jasa, keagamaan, perumahan, perkantoran, pariwisata

5. Kawasan Petudungan : Aktifitas perumahan

6. Kawasan Kulitan : Aktifitas perumahan

\subsection{Gambaran Kebijakan Penataan Ruang Dan Peraturan Zonasi Di Kawasan Pecinan}

Kawasan Pecinan Semarang dalam Peraturan Darah No 11 Tahun 2011 Tentang Rencana Tata Ruang Wilayah Kota Semarang pada pasal 69 di ayat (2) ditetapkan sebagai bagian kawasan carag budaya. Rencana pengelolaan kawasan cagar budaya meliputi: a. pelestarian pola sosial budaya masyarakat; b. pengaturan perubahan ukuran 
dan bentuk bangunan; dan c. pengembangan kegiatan kepariwisataan. Sementara pada ketentuan umum zonasi pada pasal 118 ayat (5) huruf $b$, ketentuan umum peraturan zonasi pada kawasan cagar budaya meliputi:

1) diizinkan bersyarat pendirian bangunan yang menunjang fungsi kawasan;

2) dilarang melakukan kegiatan yang mengganggu atau merusak kekayaan budaya;

3) dilarang melakukan kegiatan yang mengganggu kelestarian lingkungan di sekitar peninggalan sejarah, bangunan arkeologi, monumen; dan

4) dilarang melakukan kegiatan yang mengganggu upaya pelestarian budaya masyarakat setempat.

Pada tataran prerencanaan yang lebih rinci yaitu pada Peraturan Derah Kota Semarang No. 6 tahun 2004 tentang Rencana Derail Tata Ruang (RDTRK) Bagian Wilayah Kota ( BWK) I BLOK 1.2 aturan zonasi diterapkan dalam bentuk penetapan:

1) fungsi utama yang ditetapkan adalah:

a) Permukiman : 43,135 ha;

b) Perdagangan dan Jasa: 53,470 ha;

c) Campuran Perdagangan dan Jasa;

d) Permukiman: 14,471 ha;

e) Perkantoran : 2,220 ha;

f) Pendidikan: 2,415 ha;

g) Kesehatan: 0,521 ha;

h) Peribadatan: 5,114 ha

i) Olahraga dan Rekreasi: 0,985 ha

j) Pelayanan Umum : 8,738 ha

Dengan pemanfaatan ruang untuk utilitas:

a) Jaringan Jalan dan Utilitas : 27.273 ha;

b) Konservasi dan Ruang Terbuka Hijau Lainnya: 1,308 ha;

2) Koefisien Lantai Bangunan (KLB): 1,0.

3) Koefisien Dasar Bangunan (KDB) Jalan lokal sekunder:

a) Kawasan khusus (Balai Yasa, Perbengkelan) KDB yang direncanakan 20\% (dua puluh perseratus);

b) Perumahan KDB yang direncanakan $60 \%$ (enam puluh perseratus);

c) Campuran Perdagangan dan Jasa, Permukiman KDB yang direncanakan $60 \%$ (enam puluh perseratus); 
d) Perkantoran KDB yang direncanakan $60 \%$ (enam puluh perseratus);

e) Perdagangan dan Jasa: KDB yang direncanakan $60 \%$ (enam puluh perseratus);

f) Pasar KDB yang direncanakan $60 \%$ (enam puluh perseratus);

g) Pertokoan KDB yang direncanakan 60\% (enam puluh perseratus).

h) Fasilitas umum :

a. Pendidikan KDB yang direncanakan 50\% (lima puluh perseratus);

b. Peribadatan KDB yang direncanakan 50\% (lima puluh perseratus);

c. Kesehatan KDB yang direncanakan $50 \%$ (lima puluh perseratus);

d. Bangunan Pelayanan Umum KDB yang direncanakan 50\% (lima puluh perseratus).

Dari dokumen Pelaksanaan Program Penataan Dan Pelestarian Kota Pusaka (P3KP) Kota Pusaka Semarang, Tahun 2013, yang disusun oleh Direktorat Jenderal Penataan Ruang, Kementerian Pekerjaan Umum, pola pemanfaatan ruang dan zonasi yang ditetapkan secara rinci hanya terbatas pada pengambaran fungsi blok peruntukan dan belum mencantukkan aturan ditiap blok/zona. Pengaturan fungsi blok ini dapat dilihat pada gambar peta berikut

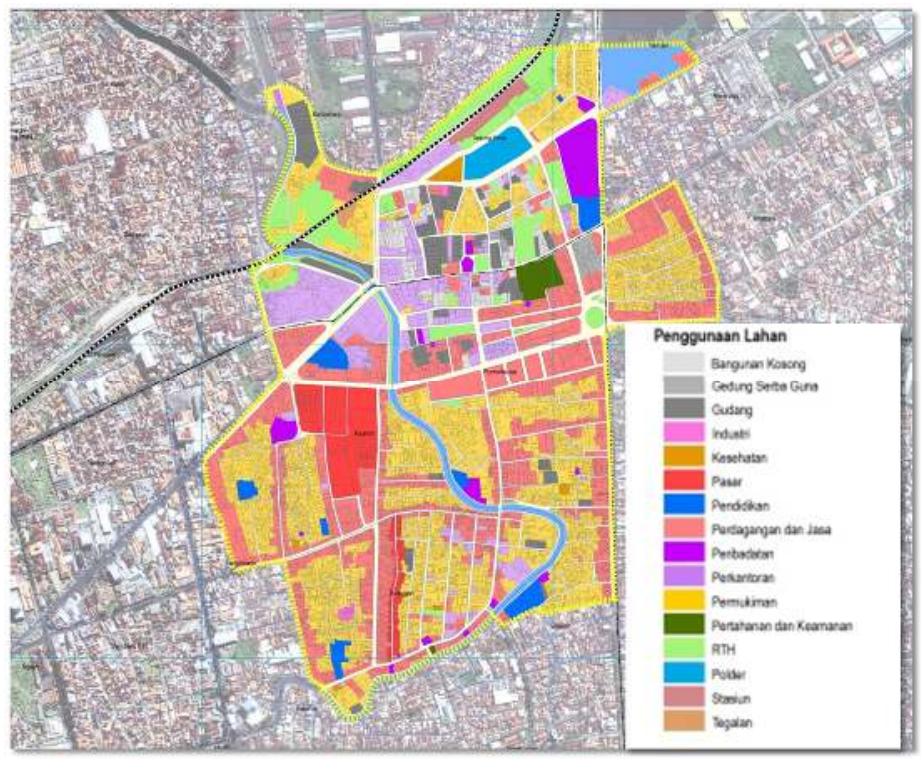

Gambar 2. Peta Penggunaan Lahan

Sumber: Dokumen Pelaksanaan Program Penataan Dan Pelestarian Kota Pusaka (P3KP) Kota Pusaka Semarang, Tahun 2013, Direktorat Jenderal Penataan Ruang, Kementerian Pekerjaan Umum 


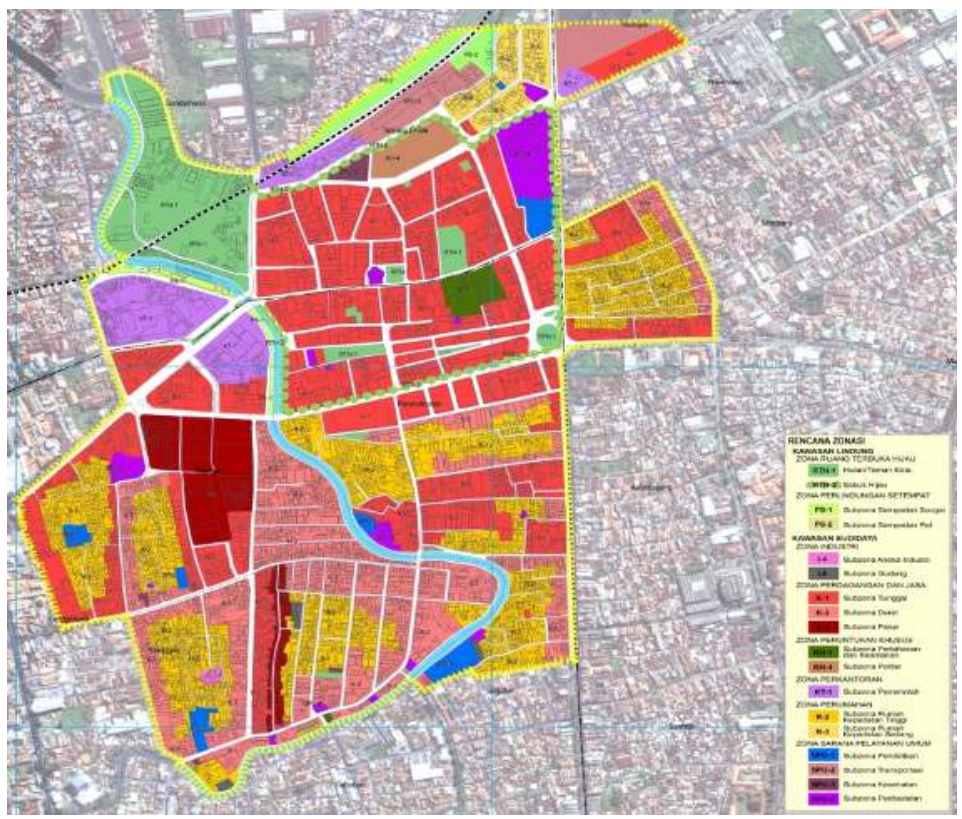

Gambar 3. Peta Rencana Zonasi

Sumber: Dokumen Pelaksanaan Program Penataan dan Pelestarian Kota Pusaka (P3KP) Kota

Pusaka Semarang, Tahun 2013, Direktorat Jenderal Penataan Ruang, Kementerian Pekerjaan Umum

Dari tiga produk tata ruang dan produk khusus penataan ruang untuk kawasan bersejarah/kawan pusaka yang ada di Kota Semarang jika kita sandingkan dengan parameter aturan zonasi yang biasa digunakan di Indonesia terlihat bahwa komponen aturan zonasi (khususnya dalam muatan RDTRK) masih belum lengkap. Aturan yang muncul sebatas penetapan fungsi kawasan, KDB, KLB dan ketinggian bangunan secara umum. Banyak kebijakan penatapan KDB dan KLB yang tidak melihat kondisi eksisting untuk KDB yang sudah mencapai $100 \%$ dan KLB sudah mencapai 3. Aturan lokal yang dibangun oleh komuniatas juga belum teradopsi dalam penetapan aturan zonasi.

Pengaturan beberapa titik ruang yang dianggap keremat dan tidak bisa diatur dengan aturan biasa seperti ruang kelenteng dan sekitarnya juga tidak tersentuh dalam aturan ini. Kondidi inilah yang kemudian dalam upaya refitalisasi kota lama banyak mencuatkan penolakan dari masyarakat terkait dengan upaya-upaya pengaturan yang hanya didasarkan pada desian tingkat tinggi dan melupakan desain populer yang diciptakan masyarakat berdasarkan kepercayaan dan sejarah pembentukan kawasan. Beberapa parameter yang ada maupun yang tidak ada dalam aturan zonasi di kawasan ini bisa dilihat pada (tabel 1).

Tabel 1. Persandingan Parameter Muatan Aturan Zonasi dan Produk Tata Ruang

\begin{tabular}{|c|c|c|c|}
\hline \multicolumn{1}{|c|}{ Parameter } & RTRW & RDTRK & P3KP \\
\hline a) Kegiatan yang diperbolehkan & v & V & v \\
\hline b) Kegiatan yang dilarang & v & x & x \\
\hline
\end{tabular}




\begin{tabular}{|c|c|c|c|}
\hline Parameter & RTRW & RDTRK & P3KP \\
\hline c) Aturan khusus untuk kegiatan & $\mathrm{x}$ & $\mathrm{x}$ & $\mathrm{x}$ \\
\hline d) Kegiatan tambahan dan aturannya & $\mathrm{x}$ & $\mathrm{x}$ & $\mathrm{x}$ \\
\hline e) Kegiatan bersyarat dan aturannya & $\mathrm{x}$ & $\mathrm{x}$ & $\mathrm{x}$ \\
\hline f) Pengecualian khusus & $\mathrm{x}$ & $\mathrm{x}$ & $\mathrm{x}$ \\
\hline g) Ketentuan luas persil (minimum/maksimum) & $\mathrm{x}$ & $\mathrm{V}$ & $\mathrm{x}$ \\
\hline $\begin{array}{l}\text { h) Ketentuan luas pekarangan (sempadan depan, samping } \\
\text {, belakang) }\end{array}$ & $\mathrm{x}$ & $\mathrm{x}$ & $\mathrm{x}$ \\
\hline i) $\mathrm{KDB}$ maksimum & $\mathrm{x}$ & $\mathrm{x}$ & $\mathrm{x}$ \\
\hline j) Luas minimum lantai bangunan & $\mathrm{x}$ & $\mathrm{v}$ & $\mathrm{x}$ \\
\hline k) Batas tinggi bangunan & $\mathrm{x}$ & $\mathrm{V}$ & $\mathrm{x}$ \\
\hline 1) Variansi & $\mathrm{x}$ & $\mathrm{x}$ & $\mathrm{x}$ \\
\hline
\end{tabular}

Sumber: Analisis Penulis, 2018.

\section{Kesimpulan dan Saran}

\section{Kesimpulan}

Peraturan zonasi di kawasan khusus cagar budaya belum melihat-rambu-rambu standar minimal prosedur perencanaan yang berlaku di Indonesia dan upaya pelestarian serta upaya penerapan karakteristik lokal secara umum belum banyak digunakan dalam peyusunan RTDRK maupun produk perencanaan spasial lainnya.

Saran

Beberapa saran yang diberikan dari hasil pembahasan ini, minimal muatan lokal harus mewarnai dan dijadikan pertimbangan dalam penentuan aturan zonasi sesusi standart minimal mencantumkan:

1. Ketentuan Kegiatan dan Penggunaan Lahan (i, T, B, X)

2. Ketentuan Intensitas Pemanfaatan Ruang (KDB, KLB, TB, KDH, Kepadatan bangunan, Kepadatan pddk max;

3. Ketentuan Tata Bangunan (GSB, GSSB, TB, TAMPILAN BANGUNAN)

4. Ketentuan Prasarana Minimal

5. Ketentuan Pelaksanaan: cara, waktu dll)

6. Ketentuan Khusus:

Komponen ketentuan khusus antara lain meliputi:

1) zona keselamatan operasi penerbangan (KKOP);

2) zona cagar budaya atau adat;

3) zona rawan bencana;

4) zona pertahanan keamanan (hankam);

5) zona pusat penelitian; 
Jurnal Planologi Vol. 15, No. 2, Oktober 2018

Available : http://jurnal.unissula.ac.id/index.php/psa

\section{DAFTAR PUSTAKA}

Alexander, Ernest, R. (1986). Approach to Planning Introducing Carrent Planning Theories, concept and Issue. Francis : Taylor \& Francis

Anonim (2010). Permen PU No. 20 Tahun 2011 tentang Pedoman Penyusunan Rencana Detail Tata Ruang.

Anonim (2011). Peraturan Daerah Kota Semarang No. 14 tahun 2011 tentang Rencana Tata Ruang Wilayah Kota Semarang 2011-2031;

Anonim (2004). Peraturan Daerah Kota Semarang No. 6 Tahun 2004 tentang Rencana Detail Tata Ruang Kota Semarang (Bagian Wilayah Kota I);

Anonim (2013). Dokumen Pelaksanaan Program Penataan Dan Pelestarian Kota Pusaka (P3KP) Kota Pusaka Semarang, Tahun 2013, Direktorat Jenderal Penataan Ruang, Kementerian Pekerjaan Umum.

Cook Jr , Robert S., (1980,) Zoning For Downtown Urban Design. Toronto : lexington Books, Massachusetts.

Farmer, W. Paul dan Gibb, Julie A., (1984). Perencanaan Penggunaan Tanah dalam Pengantar Perencanaan. Kota Jakarta: Airlangga .

Kautsary, Jamilla. (2017). Pertimbangan Makna Dan Konsep Ruang Lokal, Dalam Penataan Ruang Di Kawasan Permukiman Tradisional Pecinan Semarang, Seminar Nasional SPACE \#3 “Membingkai Multikultur dalam Kearifan Lokal Melalui Perencanaan Wilayah dan Kota”. 3 (1), 210-223.

Kautsary, Jamilla. (2015). Pelapisan Ruang Berbasis Spiritual dan Kesejarahan di Kawasan Permukiman Pecinan Semarang, Desertasi Yogyakarta : Universitas Gajah Mada.

Kautsary, Jamilla. (2015). Penolakan warga Pecinan Semarang terhadap Kebijakan dan program Revitalisasi Kawasan Pecinan, Thesis. Yogyakarta : Universitas Gajah Mada.

Liem T.J. (1931) Riwajat Semarang dari Djamannja Sam Poo Sampe Terhapoesnja Kongkoan. Tjitakan Pertama, Boekhandel Ho Kim Yoe, Semarang-Batavia..

Naughton, L. (2007). Collaborative land use planning: zoning for conservation and development in protected areas. University of Wisconsin-Madison, 4, 1-16.

Ottoe, Wayne O. (1984) Pelestarian Sejarah Dalam Pengantar Perencanaan Kota, Jakarta: Airlangga . 
Jurnal Planologi Vol. 15, No. 2, Oktober 2018

Rotich, D. (2012). Concept of zoning management in protected areas. Journal of Environment and Earth Science, 2(10), 173-183.

Widodo (1988) Chinese Settlement Changing City an Achitectural Study Of Urban Chinese Settlement in Semarang, Thesis, Lauven University, Belgium.

Zulkaidi, Denny. dan Natalivan, Petrus. (2008). Pengenalan Peraturan Zonasi, Pelatihan Penyusunan Peraturan Zonasi Ahli Teknik Zonasi I. Semarang : Badan Pembinaan Konstruksi Dan Sumberdaya Manusia Departemen pekerjaan umum. 